[2] Varga J. Overview of the clinical manifestations of systemic sclerosis (scleroderma) in adults. UpToDate Jun 2016.

[3] LeRoy EC, Medsger TA Jr. Criteria for the classification of early systemic sclerosis. J Rheumatol 2001:28:1573-6.

[4] Amato L, Gallerani I, Berti S, Fabbri P. Prescleroderma: A Distinct Stage of Systemic Sclerosis. Skinmed. 2003; 2(1).

Disclosure of Interest: None declared

DOI: 10.1136/annrheumdis-2017-eular.6927

\section{SAT0347 DISEASE MODIFYING EFFECT OF ILOPROST IN PATIENTS WITH SYSTEMIC SCLEROSIS AND POSSIBLE ROLE OF CXCL4 CHEMOKINE}

K. Stefanantoni ${ }^{1}$, I. Sciarra ${ }^{1}$, M. Vasile ${ }^{1}$, R. Palazzo ${ }^{2}$, L. Frasca ${ }^{2}$, G. Valesini ${ }^{1}$, V. Riccieri ${ }^{1} .{ }^{1}$ Dipartimento di Medicina Interna e Specialità Mediche, Sapienza Università di Roma: ${ }^{2}$ National center for research and pre-clinical and clinical evaluation of drugs- Immune-mediated diseases UNIT, Istituto Superiore di Sanità (Nat. Inst. of Health), Rome, Italy

Background: lloprost is a synthetic prostaglandine used for vascular manifestation of Systemic Sclerosis (SSc), in particular it is indicated for active digital ulcers (DU) and severe Raynaud Phenomenon (RP) (1). It acts on several receptors such as IP and EP receptors and PPRs. Iloprost is also involved in the regulation of gene expression, fibrosis and inflammation $(2,3,4)$. CXCL4 o Platelet Factor 4 , is a 70KDa CXC-chemokine synthesized in megakaryocytes and plasmacytoid dendritic cells, released after platelet activation. In SSc, it seems to be higher in patients with early diffuse SSc and it correlates with mRSS and presence of PAH (5)

Objectives: To evaluate the effect of lloprost on vascular manifestations, on disease activity and on serum levels of CXCL4 at baseline (TO) and after 1 month (T1), 3 months (T3) and 6 months (T6) of therapy.

Methods: 30 patients $(\mathrm{M} / \mathrm{F}=1 / 29$; mean age $=58.2 \mathrm{yrs}$; mean disease duration $=12.8 \mathrm{yrs}$ ) with established SSc according to ACR criteria, were enrolled. At T0, $\mathrm{T} 1, \mathrm{~T} 3$ and T6 treatment with lloprost at standard dosage we determined RP VAS, number of DU, European Scleroderma Study Group Activity Index (EScSGAI) and serum levels of CXCL4, measured using commercially available immunoassay kit (Human CXCL4/PF4 R\&D SYSTEMS ${ }^{\circledR}$ ). All patients underwent to a complete clinical, instrumental and laboratory evaluation.

Results: Regarding RP VAS, we found a statistically significant increase $(p=0.04)$ at T3, corresponding to the colder winter period, while it decreased, although not significantly at $\mathrm{T} 1$ and at $\mathrm{T} 6$, where this reduction was significant compared to T3 values $(p=0.0008)$. Considering the number of active DU, we have highlighted the same trend of the RP VAS. EScSGAI values showed a statistically significant reduction ( $\mathrm{p}=0.03$ ) comparing T3 to T6. Regarding $C X C L 4$, we found significantly higher levels in SSc patients respect to a group of healthy controls $(H C)(p=0.047)$. No significant difference was found in serum levels of CXCL4 at TO, T1,T3 and T6. Evaluating patients with higher levels of CXCL4 at baseline, respect to the average of $\mathrm{HC}$ values (CXCL4>25,000 pg/ml) (11/30 patients), we found that 7 subjects had a significant improvement in disease activity at T6 evaluated by EScSGAI $(p=0.015)$. In these patients we also detected a significant reduction in T3 CXCL4 values $(p=0.043)$ persisting and at T6, although not reaching statistical significance. Moreover higher basal levels of CXCL4 in patients with disease duration less of 60 months $(p=0.05)$ and in patients with pericardial effusion $(p=0.037)$ were detected. Besides we found significantly lower levels of CXCL4 in patients with DU history $(p=0.049)$ and esophageal involvement $(p=0.008)$.

Conclusions: Our study confirms the efficacy of lloprost on vascular manifestation of SSc and also highlights its effect on the disease activity. Moreover this drug seems to influence, in a subgroup of patients, concentrations of CXCL4, an important chemokine involved in SSc pathogenesis that deserves further investigations.

References:

[1] Kowal-Bielecka O et al. Ann Rheum Dis. 2009 May;68(5):620-8.

[2] Clapp LH et al. Prostaglandins Other Lipid Mediat. 2015.

[3] Dorris SL et al. Mediators Inflamm. 2012;2012:926968.

[4] Zhu Y et al. Respir Res. 2010 Mar 20;11:34.

[5] Van Bon et al. N Engl J Med. 2014 Jan 30;370(5):433-43.

Disclosure of Interest: None declared

DOI: 10.1136/annrheumdis-2017-eular.5731

\section{SAT0348 ASSOCIATION OF VITAMIN D DEFICIENCY WITH REDUCED IL10-PRODUCING REGULATORY B CELLS IN SYSTEMIC SCLEROSIS}

A. Mavropoulos, C. Liaskos, A. Gkoutzourelas, C.G. Katsiari, D.P. Bogdanos, L.I. Sakkas. Rheumatology and Clinical Immunology, University of Thessaly, School of Health Sciences, LARISSA, Greece

Background: IL-10-producing regulatory B cells (Bregs), also known as B10 cells, are decreased and functionally impaired in patients with systemic sclerosis (SSc), particularly in those with SSc-associated interstitial lung disease (1). As serum 25-OH-vitamin D (vitD) levels are associated with clinical aspects in patients with SSc (2), we investigated whether there is any link between vitD levels and Breg levels.
Objectives: To assess whether or not vitD deficiency in SSc is associated with the percentages of circulating IL-10-producing Breg cells.

Methods: PBMCs and serum samples were isolated from 55 patients with systemic sclerosis. Serum VitD levels were measured using a commercially available sandwich ELISA kit. Phenotypic analysis of CD19, CD24, CD27, CD38 and intracellular expression of cytoplasmic IL-10 following bacterial CpG (ODN2006) and PMA/ionomycin stimulation was examined by flow cytometry using specific fluorochrome-conjugated monoclonal antibodies (BD Biosciences). Results: Systemic sclerosis patients were divided into two groups (vitD deficient or not) based on a serum concentration cut off value of $20 \mathrm{ng} / \mathrm{ml}$. The mean vitD levels in the deficient group were $14.11 \pm 3.6 \mathrm{ng} / \mathrm{ml}(\mathrm{n}=17)$ whereas the mean vitD levels in the non-deficient group were $37.5 \pm 12.9 \mathrm{ng} / \mathrm{ml}(\mathrm{n}=38)$. IL-10-producing $B$ cells (B10 cells) were significantly decreased in vitD deficient patients compared to those with medium/high levels $(p=0.02)$. CD19+CD27+ (memory) $B$ cells were also significantly reduced in patients with VitD deficiency $(\mathrm{p}=0.004)$. In addition the ratio of naïve/memory $\mathrm{B}$ cells was significantly higher in VitD deficient patients $(p<0.05)$. Within the memory B cell fraction, the CD19+CD27+CD24hi cells also known as phenotypic memory Bregs, were mostly decreased $(p=0.001)$. There was no significant association between CD19+CD38hiCD24hi (transitional) Bregs and VitD levels.

Conclusions: Our data suggest that vitamin D deficiency may account for reduced $\mathrm{B} 10$ cells in systemic sclerosis

References:

[1] Mavropoulos et al Arthritis Rheumatol. 2016:68:494-504.

[2] Arnson $Y$ et al Autoimmun Rev. 2011;10:490-4.

Disclosure of Interest: None declared

DOI: 10.1136/annrheumdis-2017-eular.5747

\section{SAT0349 EVALUATION OF STANDARD SWALLOWING FUNCTION IN ASSESSING ASPIRATION RISK FOR PATIENTS WITH SYSTEMIC SCLEROSIS}

L. Yan, P. Yunfeng, Y. Mengru. Department of Rheumatology, Third Affiliated Hospital of Sun Yat-sen University, Guangzhou, China

Background: Swallowing dysfunction is a common symptom of systemic sclerosis, which usually induce aspiration pneumonia to aggravate lung progress. It is necessary to screen swallowing disorders effectively at an early stage.

Objectives: To investigate the value of standard swallowing function assessment (SSA) in aspiration screening for inpatients with Systemic sclerosis.

Methods: SSA and Video fluoroscopic swallowing study (VFSS) were performed in 120 inpatients with Systemic sclerosis from March 2014 to September 2016. The sensitivity, specificity, positive predictive value and negative predictive value of SSA in the diagnosis of aspiration in patients were calculated by taking VFSS examination as the gold standard. The incidence of pneumonia in SSA-positive and SSA-negative patients were compared.

Results: The diagnostic sensitivity of SSA was $81.2 \%$, the specificity was $75 \%$, the positive predictive value was $68.6 \%$ and the negative predictive value was $90.3 \%$. The incidence of pneumonia in SSA positive patients was higher than that in SSA negative patients $(54.1 \%$ vs $28.3 \%)(\mathrm{P}<0.01)$.

Conclusions: SSA is a valuable screening tool for the evaluation of aspiration risk in patients with Systemic sclerosis.

References:

[1] Systemic Sclerosis with Multiple Pulmonary Manifestations. Kotnur MR, Suresh P, Reddy VS, Sharma T, Salim NA. J Clin Diagn Res. 2016 Jun;10(6):OD16-7. doi: 10.7860/JCDR/2016/18781.8032.

[2] Progression of esophageal dysmotility in systemic sclerosis. Vischio J, Saeed F, Karimeddini M, Mubashir A, Feinn R, Caldito G, Striegel K, Rothfield N. J Rheumatol. 2012 May;39(5):986-91. doi: 10.3899/jrheum.110923.

Disclosure of Interest: None declared

DOI: 10.1136/annrheumdis-2017-eular.5441

\section{SAT0350 DOES A SYSTEMIC SCLEROSIS PATIENT'S CLINICAL PHENOTYPE DEMONSTRATE HIS AUTOANTIBODY STATUS?}

M. Boonstra ${ }^{1}$, J.A. Bakker ${ }^{2}$, M.K. Ninaber ${ }^{3}$, N. Ajmone Marsan ${ }^{4}$, T.W. Huizinga ${ }^{1}$, J.K. de Vries-Bouwstra ${ }^{1}$. ${ }^{1}$ Rheumatology; ${ }^{2}$ Clinical Chemistry and Laboratory Medicine; ${ }^{3}$ Pulmonology; ${ }^{4}$ Cardiology, LUMC, Leiden, Netherlands

Background: Although antibody status has shown to improve clinical subsetting in Systemic sclerosis (SSc), it is far from perfect. For optimal clinical subsetting as well as for evaluating the possible pathogenic role of SSc specific antibodies, it is relevant to know to what extent clinical SSc phenotypes are determined by presence of these antibodies.

Objectives: To evaluate 1. if clinical relevant subsets of SSc patients are distinguishable using only clinical data, 2. how SSc specific autoantibodies are distributed among these subsets, and 3 . whether adding antibody status to cluster analyses improves recognition of SSc subsets.

Methods: Using data from SSc patients of the Combined Care In Systemic Sclerosis (CCIS) cohort, Leiden University Medical Center, hierarchical clustering based on Ward Method was performed on the first obtained factor of principal component analysis of 7 organ systems (skin;lung;heart;kidney;muscle;vascular;gastro- 
intestinal) and time since non-Raynaud phenomenon. Clinical characteristics and prevalence of auto-antibodies within clusters was evaluated. We assessed whether adding autoantibody status as additional factor improved clinical subsetting. Results: Of 407 SSc patients included, 371 patients (91\%) fulfilled ACR/EULAR 2013 criteria. Prevalence of anti-centromere (ACA) was $37 \%$, anti-topoisomerase (ATA) $24 \%$, anti-RNAPIII $5 \%$, anti-fibrillarin $4 \%$, anti-Pm/Scl $5 \%$. Cluster analysis identified clinically recognisable clusters of SSc patients based on absence of skin involvement (cluster 1), peripheral vascular involvement (cluster 2), fibrotic complications (cluster 4), and severe vascular complications (pulmonary arterial hypertension [PH], renal crises; cluster 5). Except for cluster 4, where ATA was dominant, in all clusters ACA was the most prevalent auto-antibody. No cluster associated with any of the more rare SSc specific auto-antibodies. Adding of auto-antibodies resulted in increased clinical overlap, with a frequency of $\mathrm{PH}$ between $6-8 \%$ and a frequency of digital ulcers between $24-39 \%$ in clusters 2,4 and 5 .

Table 1. Clustering of SSc patients based on clinics

\begin{tabular}{lccccc}
\hline & $\begin{array}{c}\text { Cluster 1 } \\
(\mathrm{n}=66)\end{array}$ & $\begin{array}{c}\text { Cluster 2 } \\
(\mathrm{n}=50)\end{array}$ & $\begin{array}{c}\text { Cluster 3 } \\
(\mathrm{n}=129)\end{array}$ & $\begin{array}{c}\text { Cluster } 4 \\
(\mathrm{n}=81)\end{array}$ & $\begin{array}{c}\text { Cluster 5 } \\
(\mathrm{n}=81)\end{array}$ \\
\hline Age in years, mean (SD) & $53(14)$ & $54(14)$ & $54(14)$ & $53(16)$ & $62(12.4)$ \\
Female, \% (n) & $90(60)$ & $86(43)$ & $85(110)$ & $72(58)$ & $74(60)$ \\
Time since non-Raynaud, median (range) & $3(-3-14)$ & $10(-3-44)$ & $2(0-20)$ & $3(0-27)$ & $13(0-46)$ \\
dcSSc, \% (n) & $0(0)$ & $2(1)$ & $17(22)$ & $65(53)$ & $25(20)$ \\
Mean mRSS (SD) & $0(0)$ & $4(3)$ & $4(3)$ & $14(11)$ & $4(6)$ \\
PAH, \% (n) & $3(2)$ & $4(2)$ & $0(0)$ & $5(4)$ & $20(16)$ \\
DLCO, \%predicted, mean (SD) & $70(18)$ & $66(16)$ & $70(15)$ & $64(16)$ & $54(18)$ \\
History of renal crisis, \% (n) & $0(0)$ & $0(0)$ & $0(0)$ & $3(2)$ & $17(14)$ \\
Digital ulcers, \% (n) & $15(10)$ & $98(49)$ & $4(5)$ & $28(23)$ & $6(5)$ \\
Anti-topisomerase, \% (n) & $5(3)$ & $15(7)$ & $22(28)$ & $48(37)$ & $24(19)$ \\
Anti-centromere, \% (n) & $62(39)$ & $48(23)$ & $41(53)$ & $8(6)$ & $30(24)$ \\
\hline
\end{tabular}

Conclusions: Based on clinical data alone, relevant subgroups in SSc can be distinguished. Adding antibody status to cluster analyses increases overlap of clinical features between subgroups. These findings show that solely presence of SSc specific antibodies is of limited clinical relevance. For optimal risk stratification more complex serological findings as antibody titers might be additive.

Disclosure of Interest: None declared

DOI: 10.1136/annrheumdis-2017-eular.6004

\section{SAT0351 DIFFERENCES AMONG PATIENTS WITH INTERSTITIAL LUNG DISEASE ACCORDING TO THEIR SYSTEMIC SCLEROSIS SUBCLASSIFICATION}

M. Laffont ${ }^{1}$, I. Catellvi ${ }^{2}$, D. Castillo ${ }^{3}$, M. Millan ${ }^{2}$, C. Diaz-Torné ${ }^{2}$, P. Moya ${ }^{2}$, B.P. Magallares ${ }^{2}$, A. Laiz ${ }^{2}$, H.S. Park ${ }^{2}$, J.M. De Llobet $^{2}$, J. Casademont ${ }^{2}$ ${ }^{1}$ Reumatologia, Hospital Jose Maria Ramos Mejia, Ciudad Autónoma de Buenos Aires, Argentina; ${ }^{2}$ Reumatologia; ${ }^{3}$ Neumonologia, Hospital Universitario de la Santa Creu I Sant Pau, Barcelona, Spain

Background: Systemic Sclerosis (SSc) has been widely studied from a purely global standpoint, but only a few trials have analysed patients with interstitial lung disease (SSc-ILD) as well.

Objectives: 1. Describe the clinical features of a cohort of patients with SSC and SSc-ILD. 2. Determine whether there are disparities among different types of SSC-ILD and their progression in patients with either limited (ICSSc) or diffuse involvement (dcSSc). 3. Ascertain whether there are disparities among different types of SSc-ILD and their progression according to the SSc-specific autoantibody (AAb).

Methods: Retrospective study of a cohort of patients with ILD-SSc controlled during an SSc consultation. The following variables were collected: sex, age, SSc and ILD progress in years, type of SSc and ILD, smoking, digital ulcers (DU), pulmonary hypertension, digestive disorders, cancer, SSc treatment, corticosteroid doses and lastly, lung function tests upon diagnosis, at treatment onset, and 24 months later. Additionally, a record was kept on the types of AAb present in every SSc. Qualitative and quantitative variables were compared in relation to the clinical and immunological sub-classification. Chi-square and Student's T Tests were performed. A p-value $\leq 0.05$ was considered significant.

Results: out of 266 patients with SSc, data from 47 patients with ILD-SSc were gathered; $89.4 \%$ were female, with an age range of $66.09 \pm 15.1$ years old, and $9.85 \pm 10.2$ and $4.38 \pm 9.24$ years of progression of their SSc and ILD respectively. 33 out of 47 sustained IcSSc, and both Scl-70/ATA (29.8\%) and ACA (26.1\%) were the most frequently found AAb. Non-specific interstitial pneumonia (NSIP) was the most common ILD radiological pattern (76.6\%). Most patients with SSc underwent treatment $(51.1 \%), 24 \%$ with mycophenolate mofetil (MMF); $36.2 \%$ of the patients had been concomitantly administrated corticosteroids with a mean prednisone dose of $15.73 \pm 10.3 \mathrm{mg} / \mathrm{d}$.

Upon comparing patients with IcSSc and dcSSc, prevalence of DU was higher in those with dcSSc $(p<0.01)$, MMF was less frequently used $(p<0.02)$, rituximab was more usually employed $(p<0.03)$, and they presented worse values of FEV1/FVC ratio after 24 months of treatment $(p<0.03)$. No differences were observed as to either type of ILD or progression. However, when variables were analysed regarding AAb in SSc, patients with ACA presented both fewer DU $(p<0.02)$ and NSIP pattern $(p<0.02)$, and more frequent compromise of the small airway $(p<0.01)$, they were younger and thus, they had had shorter progression of the disease. ILD diagnosis was made significantly earlier in those patients with RNA polymerase, and later in those with anti-U1RNP. No AAb was observed associated with neoplasia. Considering the types of ILD, patients with NSIP pattern were younger ( $\mathrm{p} 0.054)$ and presented worse spirometric values.

\begin{tabular}{|c|c|c|c|c|c|c|c|c|}
\hline & $\begin{array}{l}170-5 s c \\
n-47\end{array}$ & 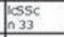 & $\begin{array}{l}\text { bessc } \\
14 \\
14\end{array}$ & 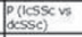 & $\begin{array}{l}\text { P(ACA vs no } \\
\text { ACA) }\end{array}$ & $\begin{array}{l}\text { P(ATA van no } \\
\text { ATA) }\end{array}$ & 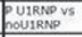 & 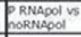 \\
\hline Age \pm So (years) & $\begin{array}{l}\begin{array}{l}66.09 \pm \\
14.1\end{array} \\
\end{array}$ & $\begin{array}{l}67.09 \pm \\
14.04\end{array}$ & $63.71 \pm 15.67$ & Ns & $<0.05$ & Nos & Ws & is \\
\hline rogress in years $\mathrm{SSc} \pm \mathrm{SO}$ & $\begin{array}{l}9.85 t \\
10.29\end{array}$ & $\begin{array}{l}3.81 \pm 15 \\
04\end{array}$ & $12.31=9.59$ & Ns & $<0.04$ & Ns & $<0.02$ & is \\
\hline Evodution in years $\mathrm{HD} \pm \mathrm{SD}$ & $\begin{array}{l}4.38 \pm \\
9.24\end{array}$ & $\begin{array}{l}4.11 \pm 9.7 \\
2\end{array}$ & $\begin{array}{l}5.02 \pm \\
3.29\end{array}$ & Ns & Ns & is & $<0.0001$ & $<0.005$ \\
\hline $\operatorname{NST}(\%)$ & $36(76.6)$ & $(72.72)$ & $12(85.71)$ & Nos & $<0.02$ & is & is & is \\
\hline Ff (\%) & $3(6,4)$ & $1(3.03)$ & $2(14.28)$ & Ns & Ns & Wis & Wis & is \\
\hline$\Phi P(\%)$ & $2(4,3)$ & $2(6.06)$ & 6 & Ns & Nis & Nis & is & $4 s$ \\
\hline Small arway compromise(\%) & $4(8.5)$ & $4(12.12)$ & p & ws & $<0.005$ & Ns & is & is \\
\hline PH (ultraound) & $3(6.4)$ & $3(9.09)$ & to & Ns & Ns & Nos & ws & ws \\
\hline pigitd ulcors (5) & $\begin{array}{l}17 \\
(36.2) \\
\end{array}$ & $7(21.21)$ & $10(71,42)$ & $<0.01$ & $<0.02$ & $<0.01$ & Wis & Wis \\
\hline Neoplasa (\%) & $5(10.6)$ & $3(9.09)$ & $2(14.28)$ & Ns & Ns & Ns & Hs & is \\
\hline $\begin{array}{l}\text { mminosuppressive } \\
\text { treament(5) }\end{array}$ & $\begin{array}{l}24 \\
(51.1)\end{array}$ & $\begin{array}{l}18 \\
(54.54) \\
\end{array}$ & $0(42.85)$ & Nos & Nos & wis & His & is \\
\hline Use of cylophosphamide (\%) & $8(17)$ & $4(12.12)$ & $4(28.57)$ & Ns & Ns & Nos & ws & is \\
\hline Use of MMF (\%) & $16(34)$ & $\begin{array}{l}125 \\
(45.45) \\
\end{array}$ & $1(7.14)$ & $<0.02$ & Ns & ws & us & vs \\
\hline Use of azathiogrine (\%) & $1(24)$ & 0 & $1(7.14)$ & Nis & Ns & Ns & us & is \\
\hline Use of riturim $3 b$ (s6) & $3(6.4)$ & 0 & $3(21.42)$ & $<0.03$ & Ns & $<0.03$ & is & is \\
\hline Use of corbooids (56) & $17(36.2)$ & $\begin{array}{l}13 \\
(39.39) \\
\end{array}$ & $4(28.57)$ & Ns & Ns & Ns & is & is \\
\hline $\begin{array}{l}\text { Doses of corbcoods } \pm \text { SD } \\
\text { molos }\end{array}$ & \begin{tabular}{|l}
$15.73 \mathrm{z}$ \\
10.31
\end{tabular} & $\begin{array}{l}14.42 \mathrm{t} \\
0.79\end{array}$ & $\begin{array}{l}200 \\
12.24\end{array}$ & Ns & $<0.02$ & Nis & Us & is \\
\hline $\begin{array}{l}\text { SFVC } \pm S D \text { upon diagnois of } \\
S S C\end{array}$ & $\begin{array}{l}32.29 \pm \\
14.6\end{array}$ & $\begin{array}{l}34.54 \\
13.41 \\
\end{array}$ & $77.89 \pm 16.67$ & Nis & Ns & Nis & Eis & $<0.001$ \\
\hline $\begin{array}{l}\text { WFivctso upon diagnosis of } \\
\text { iD }\end{array}$ & $\begin{array}{l}77.8 \pm \\
16.09\end{array}$ & $\begin{array}{l}80.292 \\
18.13 \\
\end{array}$ & $1.92 \pm 13.96$ & Nos & Nos & Nis & Wis & is \\
\hline $\begin{array}{l}\text { WFVCASD } 24 \text { months afort } \\
\text { diannosis of } 10\end{array}$ & $\begin{array}{l}77.65 \pm \\
20.94 \\
\end{array}$ & $\begin{array}{l}79.85 \pm \\
22.6\end{array}$ & $73.45 \pm 17.58$ & ws & Ns & Nis & us & vs \\
\hline $\begin{array}{l}\text { WFEVI/FVCE SO UPOn } \\
\text { diagnosis of SSC }\end{array}$ & $\begin{array}{l}83.78 t \\
14.07 \\
\end{array}$ & $\begin{array}{l}85.111 \\
15.71 \\
5.12\end{array}$ & $31.11 \pm 10.21$ & $N$ & $N=$ & Ns & is & $y=$ \\
\hline $\begin{array}{l}\text { EFFEVI/FVCTSO UDON } \\
\text { Jiagnosis of ILD }\end{array}$ & $\begin{array}{l}37.79 \pm \\
16.06\end{array}$ & $\begin{array}{l}89.565 \\
10.85 \\
\end{array}$ & $33.69 \pm 13.79$ & Ns & Ns & Nis & sis & is \\
\hline $\begin{array}{l}\text { STFEVI/FVCA SD } 24 \text { manths } \\
\text { ffter diagnosis of ILO }\end{array}$ & $\begin{array}{l}93.25 \pm 1 \\
8.93\end{array}$ & $\begin{array}{l}98.71 \pm 1 \\
7.24\end{array}$ & $\begin{array}{l}31.8 \mathrm{~s} \\
17.83 \\
\end{array}$ & $<0.03$ & Ns & 0.08 & is & is \\
\hline $\begin{array}{l}\text { WDLCOA SD upon Giagnosis } \\
\text { of SSC }\end{array}$ & \begin{tabular}{|l}
$\begin{array}{l}59.76 t \\
17.8\end{array}$ \\
\end{tabular} & $\begin{array}{l}70.93 \pm \\
18.46\end{array}$ & $67.67 \pm 17.42$ & Ns & Ns & Ns & ys & is \\
\hline $\begin{array}{l}\text { MoLCO SO upon diagnosis } \\
\text { fItLO }\end{array}$ & $\begin{array}{l}63.28 \mathrm{t} \\
18.31 \\
\end{array}$ & \begin{tabular}{|l}
$65.69 *$ \\
18.75
\end{tabular} & $57.92 \pm 16.75$ & Ns & Ns & Nis & is & ws \\
\hline 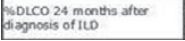 & $\mid \begin{array}{l}61.31 * \\
17.47\end{array}$ & $\begin{array}{l}\text { 63.t } \\
18.74\end{array}$ & $58.45 \pm 15.68$ & Ns & Ns & Nis & bs & is \\
\hline
\end{tabular}

Conclusions: In terms of ILD-SSc patient stratification, sub-classification by AAb appears to be more specific than the clinical sub-classification. ACA is related to less frequency of NSIP pattern. Unlike what has been described for SSc from a global point of view, in patients with ILD-SSc no association between AAb and neoplasia could be established.

Disclosure of Interest: None declared

DOI: 10.1136/annrheumdis-2017-eular.6138

\section{SAT0352 MORTALITY IN IDIOPATHIC INFLAMMATORY MYOPATHY- RESULTS FROM A SWEDISH NATIONWIDE POPULATION-BASED COHORT STUDY}

C. Dobloug ${ }^{1}$, J. Svensson ${ }^{2}$, I. Lundberg ${ }^{2}$, M. Holmqvist ${ }^{2}$. ${ }^{1}$ Oslo University Hospital, Oslo, Norway; ${ }^{2}$ Karolinska Institutet, Stockholm, Sweden

Background: Little is known about mortality in idiopathic inflammatory myopathies (IIM) compared to the general population, especially the risk development since diagnosis. In a recently published study, the 5-, and 10-year mortality was lower for IIM than previously reported, suggesting improved outcomes in recent years. Objectives: To assess the mortality following IIM diagnosis in a nationwide population-based cohort of IIM patients diagnosed 2002-2011 compared to the general population.

Methods: We used nationwide fully covering health care registers to identify all individuals who were treated by a rheumatologist, neurologist, or dermatologist for IIM and who had a listing of IIM at $\geq$ two visits within 1-12 months between 2002 and 2011, general population comparators, and death during follow up. We calculated mortality rates with $95 \%$ confidence intervals $(\mathrm{Cl})$ and compared the mortality in IIM to that in the general population using Cox proportional hazards models adjusted for age, sex, year of diagnosis, and residential area.

Results: During a median follow up of 4 years, $228(31 \%)$ of the 733 IIM patients and during a median follow up of 6 years, $888(12 \%)$ of the 7,340 general population comparators died. This corresponded to a crude mortality of $61 / 1,000$ person-years in IIM, and 20/1,000 person-years in the comparators. The cumulative mortality at 1 year after diagnosis was $10 \%$ in IIM and $1 \%$ in the general population, at 5 years it was $24 \%$ in IIM and $7 \%$ in general population, and at 10 years the proportion was $31 \%$ and $12 \%$. The overall hazard ratio (HR) $(95 \% \mathrm{Cl})$ of death comparing the NPR cohort and its comparator, was 3.5 (3.0-4.0). When restricting the outcome to cardiovascular disease-, cancer-, infection-, or pulmonary disease- specific death we noted increased mortality from all outcomes in IIM compared to the risk in the general population. When we stratified on time since diagnosis we noted an increased absolute and relative risk of death in the first year of diagnosis in particular for pulmonary disease and cancer, whereas cardiovascular mortality was a major cause of death also after 10 years after IIM diagnosis (table).

Conclusions: IIM patients are still at increased risk of death. The highest mortality 